\title{
Design and Performance Evaluation of an Indigenously Developed Small-Scale Fish-Oil Extraction Unit; a Solution for Improving Fish Farm Environments
}

\author{
Muhammad Waqar Ghous Qureshi', Zahid Mahmood-Khan ${ }^{1 *}$, Fiaz Ahmad ${ }^{1}$, \\ Muhammad Shoaib ${ }^{1}$, Hafiz Umar Farid ${ }^{1}$, Alamgir Akhtar Khan ${ }^{2}$, Jehangir Khan Sial ${ }^{3}$ \\ ${ }^{1}$ Department of Agricultural Engineering, Bahauddin Zakariya University, Multan, Pakistan \\ ${ }^{2}$ Department of Agricultural Engineering, MNS University of Agriculture, Multan, Pakistan \\ ${ }^{3}$ Department of Agricultural Engineering, PMAS Arid Agriculture University, Rawalpindi, Pakistan
}

Received: 20 October 2017

Accepted: 10 December 2017

\begin{abstract}
Aquaculture practices are considered a profitable business and are gaining popularity in Pakistan. Small farmers produce a sizeable amount of fish. The fish waste removed at the farm level and/or fishermen's end is utilized with low economic return. Fish waste produced at the farm level generally is causing environmental pollution as well. A very small amount of fish waste is used to extract the oil using crude heating technology, which is unacceptable, uneconomical, and unhygienic. Extracted oil from wastes of aquatic resources is used as raw material for production of biodiesel around the world. In view of this scenario, a study was conducted to design and develop an indigenous small-scale fishoil extraction unit. A batch-type oil extraction unit is designed in this study, which further evaluated the performance of the developed unit. The extraction unit consists of a crusher, cooker, and centrifuge system. The crusher and centrifuge system were equipped with $2 \mathrm{hp}$ and $1 \mathrm{hp}$ electric motors, respectively. The motor has a revolution capacity of about $1,450 \mathrm{rpm}$. A double jacket fully water-filled system is proposed with an agitator installed in the cooker. A $1 \mathrm{hp}$ electric motor was provided to operate an agitator at $40 \mathrm{rmp}$. The centrifuge unit has a double screening mechanism. The extraction unit is tested at a small fish farm near Muzaffargarh, Punjab, Pakistan. The fish oil is successfully separated from fish wastes with the help of a newly designed small-scale oil extraction unit. The tests showed that 90 minutes is required to process one batch of fish waste. The extraction unit has the capacity to process $15-20 \mathrm{~kg}$ of fish waste in a single batch. Research for producing bio-fuels from extracted fish oil is at its initial stages and there is a substantial need for further research to study the other economic issues related to bio-fuels and evaluate the oil extraction unit.
\end{abstract}

Keywords: fish waste, fish oil, extraction unit, biodiesel, renewable energy

*e-mail: zahidmk@bzu.edu.pk 


\section{Introduction}

Pakistan has many marine and inland fishery resources. The potential has been established as one million tons/year from the marine subsector alone. Pakistan has a continental sea area of $50,270 \mathrm{~km}^{2}$ and a coastline length of $1,120 \mathrm{~km}$. Construction of dams and barrages across rivers provide large reservoirs of about 250,000 ha for fish production. Lakes, especially in the provinces of Sind and Punjab, provide 476,800 ha for fish production [1].

Freshwater fish farming is the major aquaculture activity in the provinces of Punjab, Sind, and Khyber Pakhtunkhwa. The total area of Pakistan covered by fish ponds is about 60,500 ha, with a breakdown of about 49,170, 10,500, 560, and 240 ha in Sind, Punjab, Khyber Pakhtunkhwa, and Balouchistan, respectively. As per an economic survey of Pakistan (2016-17), a total of marine and inland fish production was found as 520,000 metric tons, out of which 375,000 metic tons was marine production and the remaining catch came from inland waters [2].

The fish produced at the farm level or collected by the fishermen along the banks of rivers, lakes, and large reservoirs is to be transported through long distances for distribution to different corners of Pakistan. Generally, fish are air-lifted or moved in rail or carried by trucks. It takes considerable time, therefore resulting in reduced product quality. In order to evade the carriage losses, frozen fish transportation becomes necessary, which is much costlier and therefore unaffordable. In view of all this, it is advisable to clean the fish at the farmgate or the fishermen's end, and this process generates solid wastes of more than $50 \%$ of the total fish waste [3], and the transportation cost is considerably curtailed. Experiments have shown that $53 \%$ of fish wastes was in liquid phase (mixture of water, oil, and suspended solids) and the extracted oil was about $11 \%$ of the total weight of the fish wastes (using $7 \mathrm{~kg}$ of wastes, about $3.71 \mathrm{~kg}$ liquid was extracted and 0.81 (768 g) oil was isolated) [4].

Conventionally, the fish waste received during cleaning is thrown away to vultures, kites, crows, and other stray animals at the farm level. This pollutes the farm environment and becomes a source of vector attraction. If the fish waste is deposited in water bodies then it leads to lowering of oxygen levels in the water due to activities of the aerobic bacteria on the organic matter [5]. Fish processing waste contains valuable byproducts which may include: fish oil ( $\omega-3$ fatty acids), proteins and amino acids, chitosan, chitin, collagen and gelatin, cosmetics, natural pigments, enzymes, animal feed, and soil fertilizers [5-7]. In areas of intense fish processing, these by-products are further processed into fishmeal, where the byproduct is waste fish oil. Fish oil is a natural source of omega-3 polyunsaturated fatty acids (PUFAs), which benefits human health [8]. Thus production of high-quality fish oil as a source of omega-3 not only depends on omega-3 rich raw material, but also on developing a suitable extraction procedure [9].
Fish oil extraction processes can be classified into 3 categories: physical, biological, and chemical. Physical extraction processes include homogenizing, heating, pressing, and filtering [10], also regarded as wet reduction [9]. Biological processes include enzymatic oil extractions and silage production through the use of enzymes from fish viscera residue (autolysis) or enzymes from other sources (hydrolysis) [11]. Although chemical solvent extraction is another well-established process to extract fish oil using organic solvents, the use of toxic solvents results in protein denaturization and loss of functional properties [12-13]. Supercritical fluid extraction technology (SCFE) has also been proposed in the extraction of compounds from natural sources, including oil recovery from seeds/biomass, raw fish, and/ or fish by-products [14].

Rubio-Rodríguez et al. [9] conducted a study to compare conventional fish oil extraction methods with supercritical fluid extraction with carbon dioxide. Adeoti and Humboldt [15] conducted an overview of developments made in fish oil extraction methodologies and concluded that the quality of oil by-product from the physical process can be good enough for biofuel application. Bako et al. [16] studied the development of a fish-oil extracting machine and tested it in various operating conditions. About 250,000 metric tons (MT) of fish waste is produced annually worldwide. The oil extracted from this waste could be converted into useful products such as green oil. When this extracted oil is directly used as fuel for engines either pure or by blending it with other solvents, the fish-extracted oil could cause problems such as carbon deposits in engine, engine durability, and lubricating oil contamination [17-18]. Converting fish oil into biodiesel would be a better approach. In the past, various studies have been conducted to convert fish oil to biodiesel and concluded the characterization of biodiesel from fish waste [4, 1921].

Recently farmers have started extracting oil from fish waste using the crude and unacceptable method of heating the fish waste in open pans that produce unhygienic oil. Apart from the poor quality of such oil, the quantity of the oil extracted from the heated/cooked fish waste is, of course, much less than the available one. Similarly, the fish meal obtained from farm extraction is not properly used. Due to problems associated with the management of the fish waste at the farm level in Pakistan, a study was conducted to develop an indigenous unit for extraction of good quality fish oil comparable to those available in

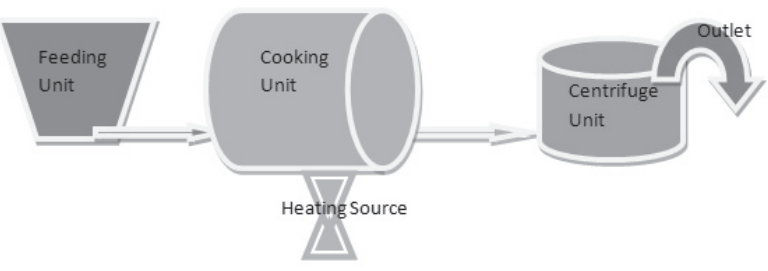

Fig. 1. Block diagram of fish-oil extraction unit. 
the market for human consumption and pharmaceutical purposes. A quality product would certainly add to income of the farmers and/or the fishermen.

\section{Material and Methods}

\section{Design and Development of the Indigenous Mechanical System}

There are different methods - cold extraction (CE) or centrifuging, wet reduction (WR), enzymatic extraction (EE) and supercritical fluid extraction (SFE) - employed in the extraction of oil from fish waste in the past [9]. In fact, the method depends on the quantity of fish to be processed. Generally, the separation of oil from the tissues of the fish starts with cooking the fish waste material for some time and later pressing or centrifuging the material for separation of oil and the solid components. All this process is generally batch type even at the large scale in the industries. The flow of operation in this study is shown in block diagram (Fig. 1).

\section{Developing the Fish-Oil Extraction Unit}

For the purposes of the present study, a mechanical unit was designed and developed to crash, cook, and centrifuge in order to efficiently extract fish oil from fish waste. The system was comprised of a main frame, raw fish waste crusher, mechanical mixer, oil extractor, drive system, and thermal unit stairs (Fig. 2).

\section{Main Frame}

The main frame is the backbone of the system to which all the other components of the system are attached in a sequential order. The main frame is further divided into the following units and all these units are mounted with each other to form a compact structure of the main frame as shown in Fig. 3.

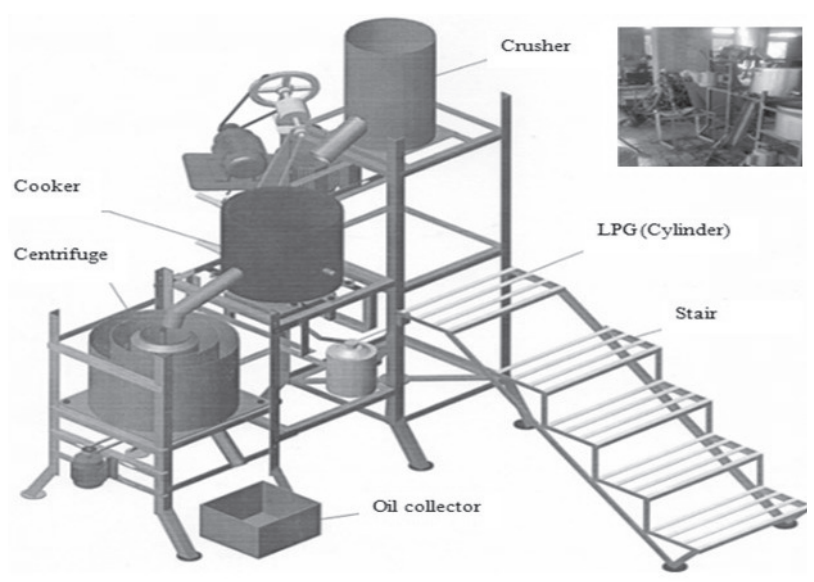

Fig. 2. 3D CAD view of newly designed oil extraction unit.

\section{Frame for Raw Fish Waste Crusher}

To support the crushing unit, a frame was fabricated with a mild steel iron angle of $46 \times 46 \times 6 \mathrm{~mm}$ used to just elevate the crusher for attaining the gravity flow of the crushed material. Its overall height is $1,820 \mathrm{~mm}$, while the crushing drum is placed at $1,095 \mathrm{~mm}$ height. Its purpose is to support all the components related to the crushing unit (Fig. 3).

\section{Raw Fish Waste Crusher}

The crushing drum was fabricated with 2-mm thick SS-304 stainless steel. The outer and inner diameters of the drum were fixed at 320 and $316 \mathrm{~mm}$, respectively. One end of the crushing drum was kept open in order to feed the raw fish waste material into the crusher drum. A base plate of SS-304 of $340 \times 340 \mathrm{~mm}$ and thickness of $5 \mathrm{~mm}$ was provided to accommodate the crushing drum shell and crusher drive mechanism (Fig. 3).

\section{Crusher Drive Mechanism}

This base plate is welded with the shell to have a compact unit while the same base plate is mounted to the frame with the help of temporary $6 \mathrm{~mm}$ diameter fasteners. In the centre of the base plate, a $21 \mathrm{~mm}$ diameter hole is provided to accommodate the $20 \mathrm{~mm}$ diameter drive shaft made of mild steel (MS). The MS shaft is supported with a ball bearing with the help of a bearing housing provided for the purpose. A V-type pulley of $33 \mathrm{~mm}$ diameter is provided at one end of the shaft for its drive while a crusher blade of $300 \mathrm{~mm}$ length and $2 \mathrm{~mm}$ thickness is provided at the other end of the shaft. The front-facing ends of the blade are sharpened for attaining the shearing as well as crushing the raw material into pulp. A single-phase electric motor of $2 \mathrm{hp}$ working on 1,450 rpm is provided for driving the crushing mechanism. A V-pulley of 70 and $30 \mathrm{~mm}$ diameter is also provided with an electric motor shaft and crusher shaft, respectively. It takes about 5 minutes to crush $10 \mathrm{~kg}$ of fish waste with crusher blades rotating at about $3,075 \mathrm{rpm}$. It is worth mentioning here that the fish waste

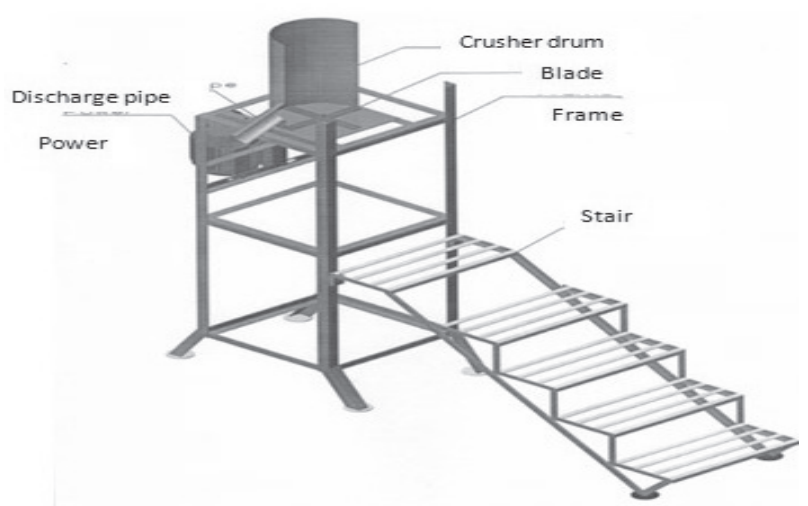

Fig. 3. 3D CAD view of crushing unit. 


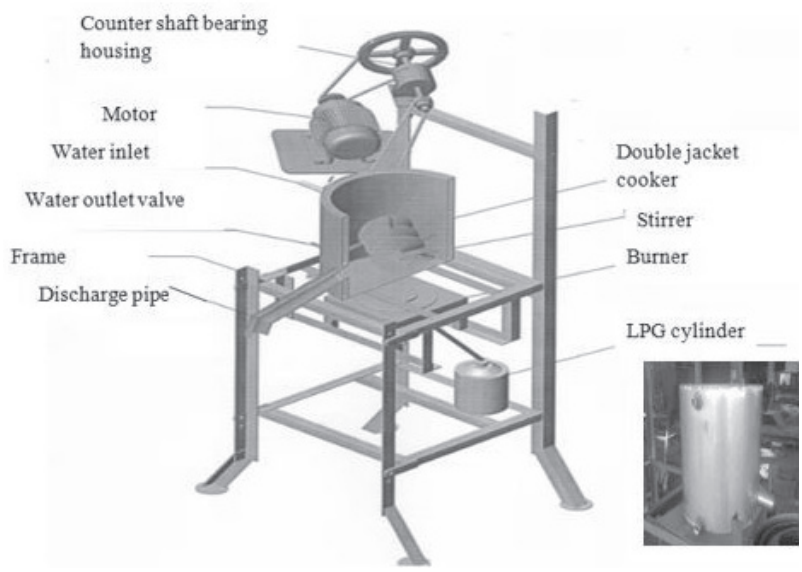

Fig. 4. 3D CAD view of double-jacket cooking unit along with view of developed cooking unit.

was not fed at once but is instead fed gradually to attain a homogeneous pulp.

\section{Double Jacket Cooker}

Crushed fish waste is shifted to a double-jacket cooker. For this purpose, a shutter is provided at the bottom of the crusher drum (Fig. 4). Once the temperature inside the cooker increases to $85^{\circ} \mathrm{C}$, it results in disintegration of fats from other fish waste. This cooker consists of a stainless steel drum of $430 \mathrm{~mm}$ external diameter. Another stainless steel drum of $376 \mathrm{~mm}$ diameter is also provided in the centre of the external drum. Furthermore, a water jacket of $27 \mathrm{~mm}$ width and 18 litre capacity is also provided.

This jacket is provided to cover the peripheral surrounding and the base of the internal drum (Fig. 4). When the jacket is filled with water, heat is provided at the base of the external drum; resultantly the water inside the jacket warms up and transforms the heat to the crushed fish waste inside the internal drum. To inject the water into the water jacket, one inlet is provided at the upper end of the jacket and an outlet is given at the lower end of the water jacket as shown in the figure below. Balltype flow control valves are used at the both inlet and outlet ports.

\section{Frame of Double-Jacket Cooker}

A frame of MS angle iron $36 \times 36 \times 4 \mathrm{~mm}$ was developed to elevate the cooker to receive the crushed fish waste material from the crusher. This frame is fastened with the frame of the crusher in order to make the unit compact. The cooker is fastened with this frame with the help of MS nut bolts of $12 \mathrm{~mm}$ dia.

\section{Stirrer}

A spiral-type stirrer is developed to agitate the material inside the cooker (Fig. 5). The stirrer gently

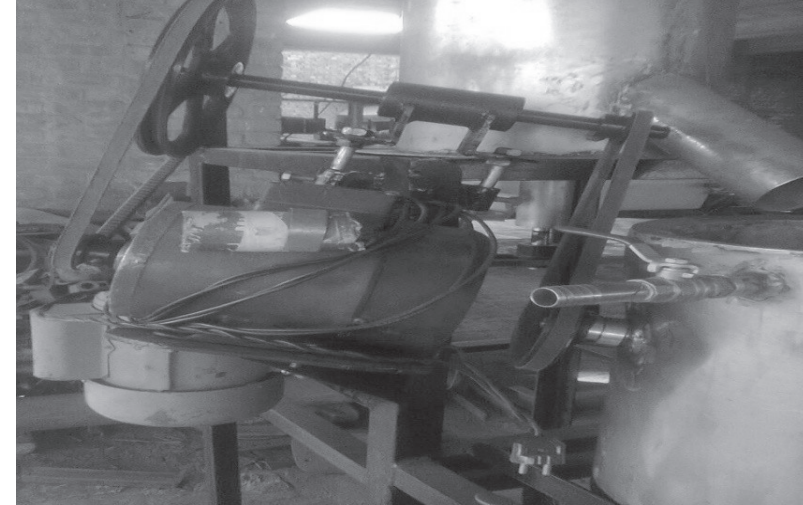

Fig. 5. Stirrer driving mechanism.

agitates the fish waste to attain homogenous temperature and thus avoid burning out the fish waste material at the base of the cooker. The spiral-shaped stirrer is made of a stainless steel sheet $60 \mathrm{~mm}$ width and $3 \mathrm{~mm}$ thick. A central drive shaft of $24 \mathrm{~mm}$ diameter is provided to mount the spiral sheet on it. A series of pegs of stainless steel round bar are permanently fixed at the outer edge of the spiral to mix the material thoroughly. The length, width, and thickness of the pegs were set as 64,17 , and $3 \mathrm{~mm}$, respectively.

\section{Stirrer Drive Mechanism}

A single-phase $1 \mathrm{hp}$ electric motor is installed to operate the stirrer at $40 \mathrm{rpm}$. The speed reduction mechanism is also set in place in order to reduce output speed of the electric motor through a set of v-belts and v-pulleys. In order to transfer power from the main electric motor to the stirrer, An A-type v-pulley of 34 $\mathrm{mm}$ diameter is mounted on the motor shaft to transmit power to another v-pulley of $234 \mathrm{~mm}$ diameter, which is mounted on the main shaft. Another pulley of 106 $\mathrm{mm}$ diameter is set on the shaft of the stirrer, and power is transmitted to this pulley using the v-belt from the pulley mounted on the end of the main shaft. With this arrangement, power of the electric motor at 1,450 rpm

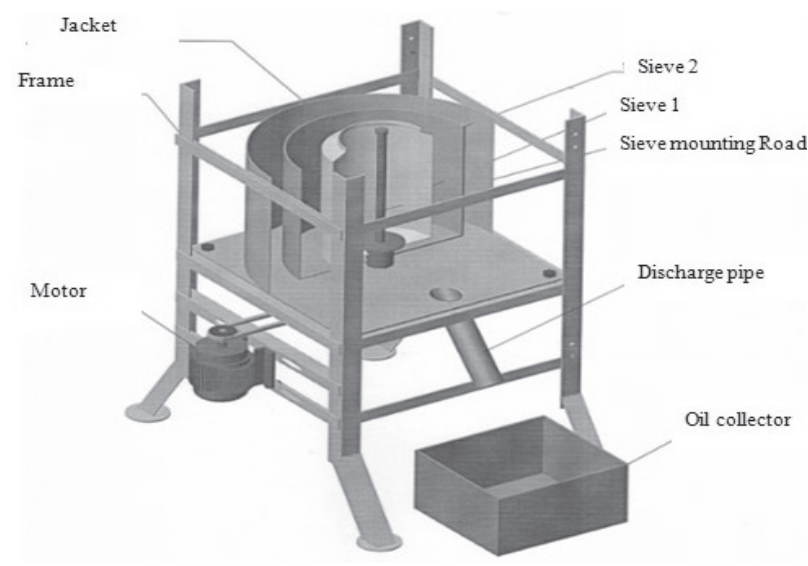

Fig. 6. 3D CAD view of oil centrifuge unit. 
is transmitted to the stirrer at $40 \mathrm{rpm}$. The stirrer is operated for one minute with an interval of 10 minutes for each batch (Fig. 5).

\section{Frame for Centrifuge/Oil Extractor}

A frame of mild steel (MS) $36 \times 36 \times 4 \mathrm{~mm}$ angle iron is developed to accommodate the centrifuge and its drive system. The centrifuge was mounted on an MS base plate $4 \mathrm{~mm}$ thick. All 3 frames were mounted together to form a single unit as and when required. The designed unit can be dismantled for the purposes of transportation to any other location (Fig. 6).

\section{Centrifuge/Oil Extractor}

From the cooker, the processed material was shifted to the centrifuge and this transfer was done through gravity flow. This developed unit is comprised of three components: the outer shell made up of a $4 \mathrm{~mm}$-thick stainless steel sheet mounted with the frame with the help of a base plate and fasteners. A central drive shaft was arranged to provide support to the rotating plate. This rotating plate is mounted to the central drive shaft and works as a platform for two sieve shells for its rotation at high rpm. The internal sieve shell of $236 \mathrm{~mm}$ diameter was fabricated with a stainless steel $3 \mathrm{~mm}$ sieve of $4 \mathrm{~mm}$ thickness.

The internal sieve shell had length of $342 \mathrm{~mm}$ with neck made of stainless steel (SS) sheet of $2 \mathrm{~mm}$ thickness and an internal diameter of $176 \mathrm{~mm}$. Processed material was received by this shell. Another sieve shell of $276 \mathrm{~mm}$ diameter with sheet thickness $2 \mathrm{~mm}$ was provided around the internal sieve shell. Both the sieve shells were seated on the rotating plate.

When the system was operated, both the sieve shells rotate at $1,800 \mathrm{rpm}$ for the period of 5 minutes per batch and the centrifugal force easily extracted the oil from the processed material. The extracted oil along with water was collected in a bin provided for the purpose, and the remaining material was collected from the inner shell. This collected material could be used for fish/cattle feed. In the collecting bin, the oil contents float over the water and can be easily drained.

\section{Operation of the Unit}

An appropriate amount of fish waste (including intestines, livers, tail, etc.) was collected at the time of cleaning the fish before loading the truck at the farm gate. The material collected was fed into the crushing unit. The waste material was shifted to the cooking unit after crushing. A heat source of the cooking unit increased the temperature inside the cooker so that the waste was cooked properly. Then the cooked material was transferred into a centrifuge for separation of oil from the solid components. After completing one batch, the crusher cylinder was loaded for the second batch and the above procedure was repeated. The oil extracted a)

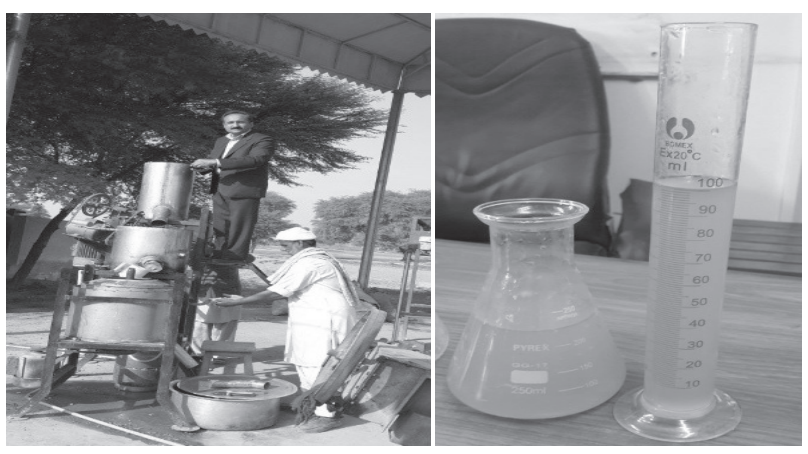

Fig. 7. a) Fish-oil extraction unit in operation and b) extracted fish oil.

from the fish waste was subjected to rigorous testing for characterizing the fish oil received from the current indigenously developed plant (Fig. 7).

\section{Experimental Design}

The newly designed system for extracting oil from the fish waste was tested for various machine parameters. A batch of $10 \mathrm{~kg}$ is used as feed rate. The $3^{3}$ factorial experiments with 3 replications were executed. The main factors are crusher speed $\mathrm{Cr}(400,500,600 \mathrm{rpm})$, cooking temperature $\mathrm{Co}\left(45,55,60^{\circ} \mathrm{C}\right)$ and centrifuge speed $\mathrm{Ce}$ (400, 600, $800 \mathrm{rpm})$.

\section{Statistical Analysis}

Statistical package STATISTIX 8.1 is used for analysis of variance (ANOVA) and parawaise comparison using LSD test at $\mathrm{p}<0.05$.

\section{Results and Discussion}

\section{Performance of the Oil Extraction Unit}

The oil extraction unit was tested with the 3 factors of crushing speed, cooking temperature, and centrifuge speed. Analysis of variance shows that crushing speed, cooking temperature, and centrifuge speed significantly affected oil, meal, and water extraction (Table 1). The interactions of crushing speed $\times$ cooking temperature, centrifuge speed $\times$ cooking temperature, and crushing speed $\times$ cooking temperature $\times$ centrifuge speed were significant at $\mathrm{p}<0.05$.

The means values show that with the increse of the cooking temperature from 45 to $65^{\circ} \mathrm{C}$ oil extraction increassed from 3.11 to $3.28 \mathrm{~L}$. Similarly, crushing speed also influenced oil extraction, as the crushing speed increased form $2,800 \mathrm{rmp}$ to $3,200 \mathrm{rpm}$, and oil extraction changed from 2.90 to $3.66 \mathrm{~L}$ (Table 2). When crushing speed was $3,200 \mathrm{rpm}$ and cooking temperature was $65^{\circ} \mathrm{C}$, oil extration was maximum. 
Table 1. Analysis of variance for various depended variables.

\begin{tabular}{|c|c|c|c|c|c|c|c|c|c|c|}
\hline \multirow[b]{2}{*}{$\mathrm{CR}$} & \multirow[b]{2}{*}{$\mathrm{Co}$} & \multicolumn{3}{|c|}{ CE1 } & \multicolumn{3}{|c|}{ CE2 } & \multicolumn{3}{|c|}{ CE3 } \\
\hline & & Y1 & Y2 & Y3 & Y1 & Y2 & Y3 & $\mathrm{Y} 1$ & $\mathrm{Y} 2$ & Y3 \\
\hline \multirow{3}{*}{2800} & 45 & 5.26 & 1.96 & 2.86 & 5.26 & 1.95 & 2.87 & 5.32 & 1.94 & 3.47 \\
\hline & 55 & 5.18 & 1.94 & 2.86 & 5.17 & 1.88 & 2.88 & 5.18 & 1.87 & 2.87 \\
\hline & 65 & 5.10 & 1.82 & 2.96 & 5.13 & 1.81 & 2.98 & 5.15 & 1.81 & 2.97 \\
\hline \multirow{3}{*}{3000} & 45 & 5.13 & 1.99 & 3.00 & 5.11 & 1.94 & 3.00 & 5.14 & 1.90 & 2.99 \\
\hline & 55 & 5.11 & 1.82 & 3.06 & 5.01 & 1.82 & 3.08 & 5.07 & 1.82 & 3.05 \\
\hline & 65 & 4.97 & 1.81 & 3.21 & 4.96 & 1.81 & 3.22 & 4.97 & 1.81 & 3.21 \\
\hline \multirow{3}{*}{3200} & 45 & 4.70 & 1.82 & 3.48 & 4.69 & 1.82 & 3.49 & 4.71 & 1.81 & 2.86 \\
\hline & 55 & 4.57 & 1.75 & 3.68 & 4.58 & 1.73 & 3.68 & 4.51 & 1.72 & 3.76 \\
\hline & 65 & 4.42 & 1.71 & 3.87 & 4.54 & 1.71 & 3.76 & 4.52 & 1.73 & 3.75 \\
\hline
\end{tabular}

Table 2. Means of oil, meal, and water extraction.

\begin{tabular}{|c|c|c|c|c|}
\hline \multirow{2}{*}{ Factors } & Levels & $\begin{array}{c}\text { Means } \\
\text { Means Water Extraction (Y1) L }\end{array}$ & $\begin{array}{c}\text { Means } \\
\text { Meal Extraction (Y2) (Kg) }\end{array}$ & $\begin{array}{c}\text { Means } \\
\text { Oil Extraction (Y3) L }\end{array}$ \\
\hline \multirow{3}{*}{$\begin{array}{c}\text { CE } \\
(\mathrm{rpm})\end{array}$} & 400 & 4.9375 & 1.8451 & 3.2221 \\
\cline { 2 - 5 } & 500 & 4.9377 & 1.8295 & 3.219 \\
\cline { 2 - 5 } & 600 & 4.9375 & 1.8236 & 3.2169 \\
\hline \multirow{3}{*}{$\begin{array}{c}\mathrm{CO} \\
\left({ }^{\circ} \mathrm{C}\right)\end{array}$} & 45 & 5.0348 & 1.9019 & 3.1141 \\
\cline { 2 - 5 } & 55 & 4.9318 & 1.8168 & 3.2166 \\
\hline \multirow{3}{*}{$\begin{array}{c}\mathrm{CR} \\
(\mathrm{rpm})\end{array}$} & 3000 & 4.8624 & 1.7795 & 2.9043 \\
\cline { 2 - 5 } & 3200 & 5.1941 & 1.8869 & 3.0914 \\
\hline
\end{tabular}

The combined effect of cooking temperature and crushing speed showed a significant effect on oil extraction. Similarly, the intractional effect of centrifuge speed and crushing speed, and the interactional effect of centrifuge speed and cooking temperature on oil extraction were found to be significant as shown in Fig. 8. A direct relationship is found between the yield of extracted oil from fish waste and all factors under consideration, including cooking temperature, crushing speed, etc.

The results indicate that with the increase in cooking temperature from 45 to $65^{\circ} \mathrm{C}$, meal extaction changed from 1.90 to $1.78 \mathrm{~kg}$. Similarly, the mean values of meal extraction changed with the increasing effect of crushing speed and centriguge speed.

The interactional effect of cooking temperature and crushing speed showed a significant effect on meal extraction. Similarly, the intractional effect of centrifuge speed and crushing speed and interactional effect of centrifuge speed and cooking temperature on meal extraction were significant, as shown in Fig. 9. A decreasing trend was observed for all factors and their levels.
The results indicated that with the increase in cooking temperature from 45 to $65^{\circ} \mathrm{C}$, mean water extaction values
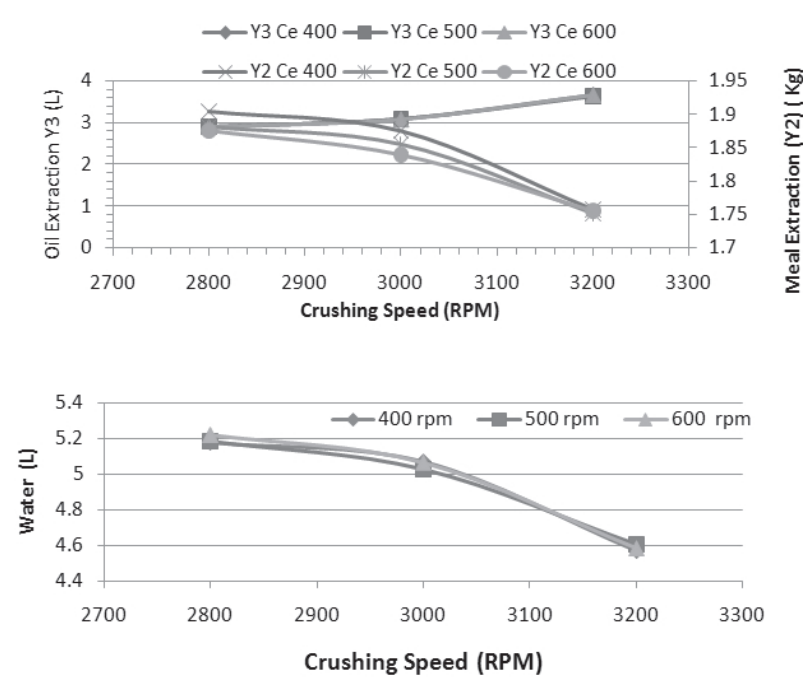

Fig. 8. Effect of crushing and centrifuge speed on oil, meal, and water extraction. 

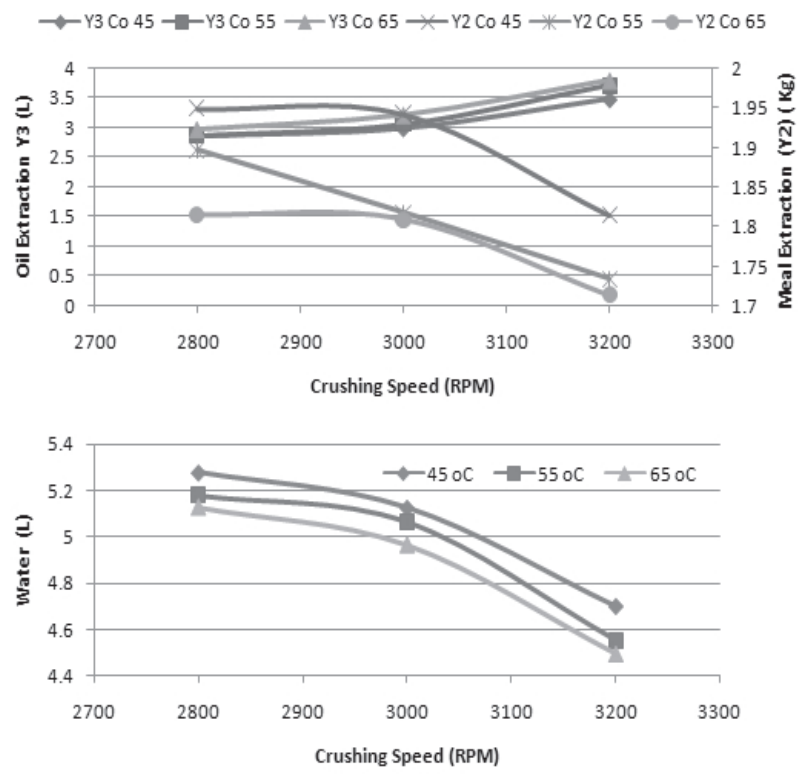

Fig. 9. Effect of cooking temperature crushing speed on oil, meal, and water extraction.

changed. Similarly, the mean values of meal extraction changed with the increasing effect of crushing speed and centrifuge speed.

The interactional effect of cooking temperature and crushing speed showed a significant effect on meal extraction. Similarly, the interactional effect of centrifuge speed and crushing speed, and the interactional effect of centrifuge speed and cooking temperature on meal extraction were significant, as shown in Fig. 10. A decreasing trend was observed for all factors and their levels. The results are in agreement with the study
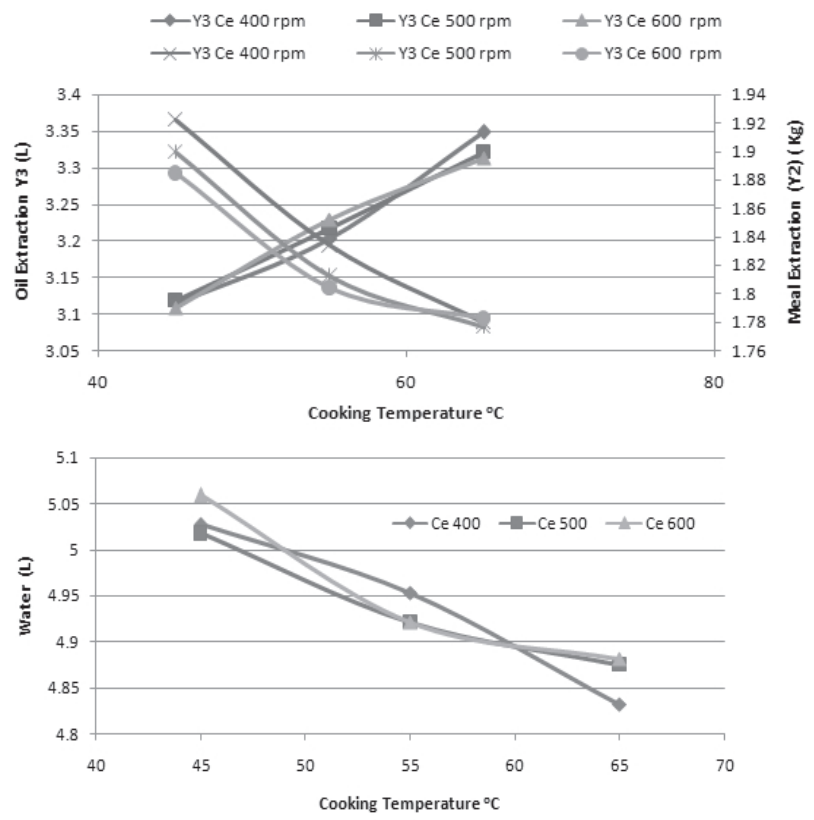

Fig. 10. Effect of cooking temperature centifuge speed on oil, meal, and water extraction. of Yahyaee, et al. [4], who found that $53 \%$ of fish waste was in liquid phase (mixture of water, oil, and suspended solids) and the extracted oil was about $11 \%$ of the total weight of the fish waste (using of $7 \mathrm{~kg}$ of wastes, about $3.71 \mathrm{~kg}$ liquid was extracted and 0.81 (768 g) oil was isolated). Bako et al. [16] showed that mechanical extraction is a suitable method for extracting fish oil because of its high yield and high oil purity. Bamgboye and Adejumo [22] reported that reduction in oil yield was observed with an increase in speed of rotation of the shaft. Akinoso et al. [23], while evaluating the effects of compressive stress, feeding rate, and speed of shaft screw press on palm kernel oil yield observed the same trend of increases in oil yield with increased speed.

\section{Conclusions}

There is a great potential for oil extracted from fish waste and subsequently used in the formation of biodiesel. Research for producing bio-fuels from fish oil is in the beginning stages and there is a substantial need for more research to study the other economic issues related to biofuels. There is also a considerable potential for utilizing fish oil as bio diesel in Pakistan. An efficient fish oil extraction unit can be manufactured indigenously for a small farmer. The machine parameter on which the unit was designed significantly affects fish oil extraction. With an increase of cooking temperature, crushing speed, and centrifuge speed, the extraction of fish oil and meal were significantly affected. The extraction unit should be used at the farm level so that fish waste can be handled properly along with an increase in farm income.

\section{Acknowledgements}

The authors wish to express their sincere thanks to the Agricultural Mechanization Research Institute Multan and Agritech Industry Multan, Pakistan for their cooperation and assistance in facilitating the present research. Furthermore, the authors also acknowledge the financial support provided by Bahauddin Zakariaya University Multan-Pakistan for developing the fish-oil extraction unit.

\section{References}

1. FAO Fisheries and Agriculture Department: Country profile-Pakistan. www.fao.org. Retrieved 25 August 2010.

2. Economic Survey of Pakistan, Ministry of Finance, Government of Pakistan 2017. http://www.finance.gov. $\mathrm{pk} /$ survey/chapters_17/02-Agriculture.pdf. Retrieved 30 November 2017.

3. SHAHIDI F. Maximixing the Value of Marine by-products. CRC Press, Boca Ratón USA. 2007. 
4. YAHYAEE Y., GHOBADIAN B., NAJAFI G. Waste fish oil biodiesel as a source of renewable fuel in Iran. Renewable Sustain Energy Rev. 17, 312. 2013.

5. GHALY A.E., RAMAKRISHNAN V.V., BROOKS M.S., BUDGE S.M., DAVE D. Fish processing wastes as a potential source of proteins, amino acids and oils: A critical review. J. Microbial Biochem Tech. 5 (4), 107, 2013.

6. NORZIAH M.H., NURAINI J., LEE K.Y. Studies on the extraction and characterization of fish oil from wastes of seafood processing industry. Asian J. Food Agro-Industry. 2 (04), 959, 2009.

7. ARVANITOYANNIS I.S., KASSAVETI A. Fish industry waste: treatments, environmental impacts, current and potential uses. Int. J. Food Sci Tech. 43 (4), 726, 2008.

8. CHOW C.K. Fatty Acids in Foods and their Health Implications, second Ed. (revised and expanded. Marcel Dekker Inc., New York-Basel. 2000.

9. DE-DIEGO M.S.N.R.R., BELTRÁN S., JAIME I., SANZ M.T., ROVIRA J. Supercritical fluid extraction of fish oil from fish by-products: A comparison with other extraction methods, J. Food Engg. 109, 238, 2012.

10. JAYASINGHE P., HAWBOLDT K. A review of bio-oils from waste biomass: focus on fish processing waste. Renew Sustain Energy Rev. 16 (1), 798, 2012.

11. LINDER M., FANNI J., PARMENTIER M. Proteolytic extraction of salmon oil and PUFA concentration by lipases. Marine Biotech. 7 (1), 70, 2005.

12. SAHENA F., ZAIDUL I.S.M. JINAP S., JAHURUL M.H.A., KHATIB A., NORULAINI N.A.N. Extraction of fish oil from the skin of Indian mackerel using supercritical fluids. J Food Eng. 99 (1), 63, 2010.

13. MBATIA B.N. Valorisation of fish waste biomass through recovery of nutrition lipids and biogas [Doctoral Thesis]. Lund, Sweden: Lund University; 2011.
14. REVERCHON E., DE MARCO I. Supercritical fluid extraction and fractionation of natural matter. J Supercrit Fluid. 38 (2), 146, 2006.

15. IBRAHEEM A., ADEOTI I.A., HAWBOLDT K. A review of lipid extraction from fish processing by-product for use as a biofuel. Biomass Bioenergy. 6, 330, 2014.

16. BAKO T., UMOGBAI V.I., OBETTA S.E. Development of a fish oil extracting machine, Asian J Sci. Tech., 5 (8), 43, 2014.

17. STEIGERS J.A. Demonstrating the use of fish oil as fuel in a large stationary diesel engine. Advances in sea food byproducts: conference proceedings. Alaska Sea Grant, Fairbanks, AK. 187, 2002.

18. STEIGERS J. Alaska fish oil as a biodiesel feedstock. Presented in the challenging face of energy in rural Alaska 2005.

19. HAMED M., EL-MASHAD, ZHANG R., ROBERTO J., BUSTILLOS A. A two-step process for biodiesel production from salmon oil. Biosys Engg. 2008, 220, 2008.

20. OTTO A., JAN-ERIK W. Residual animal fat and fish for biodiesel production potentials in Norway. Biomass and Bioenergy 34, 1183, 2010.

21. LIN C.Y., LI R.J., Engine performance and emission characteristics of marine fish-oil biodiesel produced from the discarded parts of marine fish. Fuel Proc Tech. 90, 883, 2009.

22. BAMGBOYE A.I., ADEJUMO A.O.D. Development of a sunflower oil expeller. Agricultural Engineering International: The CIGR E J. 9, 1, 2007.

23. AKINOSO R., RAJIA O., IGBEKA J.C. Effects of compressive stress, feeding rate and speed of rotation on palm kernel oil yield. J. Food Engg. 93, 427, 2009. 